\title{
Variants of transshipment problem
}

\author{
Archana Khurana
}

Received: 22 April 2014 / Accepted: 22 January 2015 /Published online: 3 April 2015

(C) The Author(s) 2015. This article is published with open access at SpringerLink.com

\begin{abstract}
Purpose In a transshipment problem all the sources and destinations can function in any direction thus transshipment is very useful to reduce the transportation cost. Sometimes, because of budget/political constraint, the total flow in transshipment problem is also specified by some external decision maker and the optimal solution of such problems is of realistic interest to the decision maker. This has motivated me to discuss impaired and enhanced flow in a transshipment problem. Method Algorithms are provided for solving such transshipment problems by transforming the original problem into an equivalent transportation problem by adding an additional row and a column.

Results The optimal solution of the transformed transportation problem gives the optimal solution of the given transshipment problem having the same objective function value. I have considered both balanced as well unbalanced transshipment problems and have also discussed various situations emerging out of unbalanced capacitated transshipment problems in the form of inequalities.

Conclusion The algorithms and transformations are easy to understand and serve the managers by providing the solution to a variety of distribution problems. Numerical examples are solved to illustrate the theory and computational work for various higher dimensional problems is also included.
\end{abstract}

Keywords Transportation problem .

Transshipment problem $\cdot$ Restricted flow $\cdot$ Enhanced flow .

Unbalanced transportation problem

\section{Mathematics subject classification $90 \mathrm{C} 05 \cdot 90 \mathrm{C} 08$}

A. Khurana $(\bowtie)$

School of Basic and Applied Sciences, Guru Gobind Singh Indraprastha University, Dwarka, Sector-16C, Delhi 110075, India

e-mail: archana2106@gmail.com

\section{Introduction}

A transportation problem refers to a class of linear programming problems that involves selection of most economical shipping routes for transfer of a uniform commodity from a number of sources to a number of destinations. In case of an unbalanced transportation problem, the total availability is not equal to total demand, thus some of the source and/or destination constraints are satisfied as inequalities. When one wishes to keep reserve stocks at the sources for emergencies thereby restricting the total transportation flow to a known specified level, it results in a transportation problem with impaired flow. For example, stockiest reserves the goods viz. medicines, food grains \& other items at warehouses for emergencies. On the other hand, when there is an extra demand in the market due to high storage cost at some sources or during festive / marriage seasons or during fire / military services, the total flow needs to be enhanced compelling some of the factories to increase their productions in order to meet this extra demand. The total flow from the factories in the market is now increased by the amount of extra demand. This results in a transportation problem with enhanced flow.

In case of transportation problem, the amount to be sent from each origin, the amount to be received at each destination, the cost per unit shipped from any origin to any destination are specified and transshipment is not considered. Thus each point acts as shipper only or as a receiver only. We may extend this problem to permit transshipment with the additional feature that shipments may go via any sequence of points rather than being restricted to direct connections from one origin to one of the destination. It is assumed that a large amount of material to be shipped is available at each point and act as stockpile, which can be drawn or replenished. The unit cost of shipment from a point considered as a shipper to the same point considered as receiver is set equal to zero. The solution to the transshipment problem lies in the fact that 
withdrawals from and compensating additions to the stockpiles are equivalent to transshipment.

The transshipment problem formulation has been and is still being used extensively by researchers to solve spatial equilibrium and plant location problems as well.

In the transshipment problem all the sources and destinations can function in any direction. Usually, in the absence of the transshipment, the transportation cost goes higher. Hence transshipment is also very useful to reduce the transportation cost. Both the transportation problem and the transshipment problem are also quite widely used for planning bulk distribution, especially in the USA where the (road) distances travelled are large.

Cost-time transportation problem have extensively been studied by many researchers in the past years. Klingman and Russel [1] introduced a specialized method for solving a transportation problem with several additional linear constraints. Brigden [2] considered the transportation problem (TP) with mixed constraints. Brigden [2] solved this problem by considering a related standard transportation problem having two additional supply points and two additional destinations. After that Gupta et al. [3, 4] have also worked on linear and non-linear transportation problems. In the recent years, indefinite Quadratic Transportation Problem has also been studied [5-7]. Dahiya and Verma [8] studied capacitated transportation problem with bounds on the rim conditions.

Transshipment Problem was first introduced by Orden [9]. He gave an extension of the original transportation problem to include the possibility of transshipment i.e., any shipping or receiving point is also permitted to act as an intermediate point. The Transshipment technique is used to find the shortest route from one point in a network to another. The problem of determining simultaneously the flows of primary products through processors to the market as final products has been formulated alternatively as a transshipment model by King and Logan [10] and as a reduced matrix model by Rhody [11]. An extension of this problem to a multiregional, multiproduct and multiplant problem formulated in the general linear programming model has been proposed by Judge et al. [12]. Afterwards, various alternatives formulations of the transshipment problem within the framework of the transportation model that permits solution of problems of the type discussed by King and Logan without the need for subtraction of artificial variables were discussed by Hurt and Tramel [13]. In 1985, Garg and Prakash [14] studied time minimizing transshipment problem. Recently in 2014, 2011, Khurana et al. $[15,16]$ studied three - dimensional time minimizing transshipment problem.

In literature, much effort has been concentrated on transportation problems as well as transshipment problems with equality constraints. The transportation problem with restricted flow was studied by Thirwani and Arora [17]. In 2006, Khurana and Arora [18] studied linear plus linear fractional transportation problem for restricted as well as enhanced flow. Later, Khurana et al. [5] studied the indefinite quadratic transportation problem with restricted flow in 2009 and then in 2011 they [6] studied the same problem with enhanced flow. Since the total flow in transportation/transshipment problem is also specified by some external decision maker because of budget/political consideration, the optimal solution of such problem is of practical interest to the decision maker and has motivated us to discuss such problems. Transshipment problems with mixed constraints were studied by Khurana et al. in 2011 [19]. Later Khurana et al. studied multiindex transshipment problems [20, 21]. Later capacitated transshipment problem with bounds on rim conditions was studied by Khurana et al. [22].

In this paper the author has given an algorithm to solve a linear transshipment problem with impaired and enhanced flow. The literature search reveals no systematic method for finding an optimal solution of the same. We consider a generalization of the standard transshipment model in which the origin and destination constraints take not only the equality form but also of inequality. It is shown that the models are transformed to an equivalent standard transportation problem be adding an additional row and a column. We have solved the problems for balanced as well unbalanced cases and have discussed the various situations emerging out of unbalanced transshipment problems. The algorithms and transformation are easy to understand and to apply. The solution method can serve as an effective tool to the managers having production allocation problems.

\section{Mathematical formulation of transshipment problem}

Suppose that, we have $\mathrm{m}$ origins and $\mathrm{n}$ destinations. Since in a transshipment problem, any origin or destination can ship to any other origin or destination it would be convenient to number them successively so that the origins are numbered from 1 to $\mathrm{m}$ and the destinations from $\mathrm{m}+1$ to $\mathrm{m}+\mathrm{n}$.

Let $a_{i}$ be the quantities available at the origins and $b_{j}$ be the demands at the destinations and

$$
\sum_{i=1}^{m} a_{i}=\sum_{j=m+1}^{m+n} b_{j}
$$

Let $x_{i j}(i, j=1,2, \ldots, m+n, j \neq i)$ be the quantities shipped from station $i$ to station $j$ and $c_{i j}$ be the unit cost of shipping 
from $i$ to $j(i, j=1,2, \ldots, m+n, j \neq i)$ where $c_{i j}$ need not be the same as $\mathrm{c}_{\mathrm{ji}}$.

We define a supply point to be a point that can send goods to another point but cannot receive goods from any other point. Similarly, a demand point is a point that can receive goods from other points but cannot send goods to any other point. A transshipment point is a point that can receive goods from other points and send goods to other points. Thus the Transshipment Problem may be written as

$$
\text { Minimize } z=\sum_{i=1}^{m+n} \sum_{\substack{j=1 \\ j \neq i}}^{m+n} c_{i j} x_{i j}
$$

subject to

$$
\begin{array}{ll}
\sum_{\substack{j=1 \\
j \neq i}}^{m+n} x_{i j}-\sum_{\substack{j=1 \\
j \neq i}}^{m+n} x_{j i}=a_{i} \quad \forall i=1,2, \ldots \ldots, m \\
\sum_{\substack{i=1 \\
i \neq j}}^{m+n} x_{i j}-\sum_{\substack{i=1 \\
i \neq j}}^{m+n} x_{j i}=b_{j} & \forall j=m+1, m+2, \ldots \ldots, m+n \\
x_{i j} \geq 0 & \forall i, j=1,2, \ldots \ldots ., m+n ; i \neq j
\end{array}
$$

The above formulation is a linear programming problem, which is similar to a transportation problem but not exactly since the coefficients of $\sum \mathrm{x}_{\mathrm{ji}}$ 's are -1 .

Here, originally we have $m$ supply points and $n$ demand points. However, we make all the supply and demand point as transshipment points resulting in $\mathrm{m}+\mathrm{n}$ transshipment points.

Thus the problem however may easily be converted to a standard transportation problem.

$$
\text { Let } \begin{aligned}
t_{i} & =\sum_{\substack{j=1 \\
j \neq i}}^{m+n} x_{j i} \quad \forall i=1,2, \ldots \ldots, m \text { and } \\
t_{j} & =\sum_{\substack{i=1 \\
i \neq j}}^{m+n} x_{j i} \quad \forall j=m+1, m+2, \ldots \ldots, m+n
\end{aligned}
$$

where $t_{i}$ represents the total amount of transshipment through the $i$ th origin and $t_{j}$ represents the total amount shipped from the jth destination as transshipment.

$$
\begin{array}{ll}
\sum_{j=1}^{m+n} x_{i j}=a_{i}+T & \forall i=1,2, \ldots \ldots, m \\
\sum_{j=1}^{m+n} x_{i j}=T & \forall i=m+1, m+2, \ldots \ldots, m+n \\
\sum_{i=1}^{m+n} x_{i j}=T & \forall j=1,2, \ldots \ldots, m
\end{array}
$$

Let $\mathrm{T}>0$ be sufficiently large number so that $\mathrm{t}_{\mathrm{i}} \leq \mathrm{T}$, for all $\mathrm{i}$ and $\mathrm{t}_{\mathrm{j}} \leq \mathrm{T}$ for all $\mathrm{j}$

We now write $t_{i}+x_{i i}=T$, then the nonnegative slack variable $\mathrm{x}_{\mathrm{ii}}$ represents the difference between $\mathrm{T}$ and the actual amount of transshipment through the ith origin.

Similarly, if we let $\mathrm{t}_{\mathrm{j}}+\mathrm{x}_{\mathrm{jj}}=\mathrm{T}$, then the nonnegative slack variable $x_{j j}$ represents the difference between $T$ and the actual amount of transshipment through the jth destination.

Thus the transshipment problem reduces to

Minimize $\quad z=\sum_{i=1}^{m+n} \sum_{\substack{j=1 \\ j \neq i}}^{m+n} c_{i j} x_{i j}$

subject to$$
\sum_{i=1}^{m+n} x_{i j}=b_{j}+T \quad \forall j=m+1, m+2, \ldots \ldots, m+n
$$$$
\begin{array}{ll}
x_{i j} \geq 0 & \forall i, j=1,2, \ldots \ldots ., m+n ; i \neq j \\
c_{i i}=0 & \forall i=1,2, \ldots \ldots \ldots, m+n
\end{array}
$$

The above mathematical model represents a standard transportation problem with $(m+n)$ origins and $(m+n)$ destinations.

We shall construct the transportation tableau for above problem (P2) as follows: A row in the tableau will be needed for each supply point and transshipment point, and a column will be needed for each demand point and transshipment point. Each supply point will have a supply equal to its original supply, and each demand point will have a demand equal to its original demand. Let $\mathrm{T}=$ total available supply. Then each transshipment point will have a supply equal to point's original supply $+\mathrm{T}$ and a demand 
equal to point's original demand $+\mathrm{T}$. This ensures that any transshipment point that is a net supplier will have a net outflow equal to the point's original supply, and, similarly, a net demander will have a net inflow equal to the point's original demand. Although, we don't know how much will be shipped through each transshipment point, we can be sure that the total amount will not exceed T. This explains why we add $\mathrm{T}$ to the supply and demand at each transshipment point. By adding the same amounts to the supply and demand, we ensure that the net outflow at each transshipment point will be correct, and we also maintain a balanced transportation tableau.

Note1: The total amount shipped from an origin must be equal to the amount it produces plus what it transships. Similarly, the total amount received at a destination must be equal to its demand plus what it transships.

Note2: $\mathrm{T}$ can be also interpreted as a buffer stock at each origin and destination. Since we assume that any amount of goods can be transshipped at each point, T should be large enough to take care of all transshipments. It is clear that the volume of goods transshipped at any point cannot exceed the amount produced or received and hence we take $\mathrm{T}=\max \left(\sum_{i=1}^{m} a_{i}, \sum_{j=m+1}^{m+n} b_{j}\right)=$ Buffer stock.

Note3: The solution of the problem (P2) contains $2 \mathrm{~m}+2 \mathrm{n}-1$ basic variables. However, $\mathrm{m}+\mathrm{n}$ of these variables appearing in the diagonal cells represent the remaining buffer stock and if they are omitted, we have $(m+n-1)$ basic variables of our interest.

Remark1: An optimal solution of the transportation problem (P2) gives the optimal solution of the transshipment problem (P1) having the same objective function value.

\section{Transshipment problem with impaired flow}

Sometimes, situations may arise where one wishes to keep reserve stocks at the sources, say for emergencies, thereby restricting the total transportation flow to a known specified level, say P. Then we have

$\sum_{i=1}^{m} \sum_{j=m+1}^{m+n} x_{i j}=P \quad$ or $\quad \sum_{i=1}^{m+n} \sum_{j=1}^{m+n} x_{i j}=P^{\prime}$

where $P^{\prime}=P+(m+n) T$
The transshipment problem with impaired flow is given by

Minimize $\quad z=\sum_{i=1}^{m+n} \sum_{\substack{j=1 \\ j \neq i}}^{m+n} c_{i j} x_{i j}$

subject to

$\sum_{j=1}^{m+n} x_{i j} \leq a_{i}+T \quad \forall i=1,2, \ldots \ldots \ldots \ldots, m$

$\sum_{j=1}^{m+n} x_{i j}=T \quad \forall i=m+1, \ldots \ldots \ldots . ., m+n$

$\sum_{i=1}^{m+n} x_{i j}=T \quad \forall j=1,2, \ldots \ldots \ldots \ldots, m$

$\sum_{i=1}^{m+n} x_{i j} \leq b_{j}+T \quad \forall j=m+1, \ldots \ldots \ldots, m+n$

$\sum_{i=1}^{m+n} \sum_{j=1}^{m+n} x_{i j}=P^{\prime} \quad\left(P^{\prime}<\min \left\{\sum_{i=1}^{m} a_{i}+(m+n) T, \sum_{j=m+1}^{m+n} b_{j}+(m+n) T\right\}\right)$

$x_{i j} \geq 0$

$\forall i, j=1,2, \ldots \ldots \ldots \ldots \ldots, m+n(i \neq j)$

$c_{i i}=0 \quad \forall i=1,2, \ldots \ldots \ldots \ldots, m+n$

The flow constraint in the problem (P3) implies that a total $\left\{\left(\sum_{i=1}^{m} a_{i}+(m+n) T\right)-P^{\prime}\right\}$ of source reserves has to be kept at the various sources and a total $\left\{\left(\sum_{j=m+1}^{m+n} b_{j}+(m+n) T\right)-P^{\prime}\right\}$ of destination slacks are to be retained at the various destinations. Therefore, an extra destination to receive the source reserves and an extra source to fill up the destination slacks are introduced. Hence the related transportation problem with restricted flow is given as below.

Minimize $\quad z=\sum_{i=1}^{m+n+1} \sum_{j=1}^{m+n+1} c_{i j} y_{i j}$ 
subject to

$$
\begin{aligned}
& \sum_{j=1}^{m+n+1} y_{i j}=a_{i}^{\prime} \quad \forall i=1,2, \ldots \ldots, m+n, m+n+1 \\
& \sum_{i=1}^{m+n+1} y_{i j}=b_{j}^{\prime} \quad \forall j=1,2, \ldots \ldots, m+n, m+n+1 \\
& \sum_{i=1}^{m+n} \sum_{j=1}^{m+n} x_{i j}=P^{\prime} \\
& a_{i}^{\prime}= \begin{cases}a_{i}+T & \forall i=1, \ldots \ldots \ldots, m \\
T & \forall i=m+1, \ldots \ldots \ldots, m+n \\
\sum_{j=1}^{m+n} b_{j}^{\prime}-P^{\prime} & \text { for } i=m+n+1\end{cases} \\
& b_{j}^{\prime}= \begin{cases}T & \forall j=1, \ldots \ldots \ldots \ldots, m \\
b_{j}+T & \forall j=m+1, \ldots \ldots \ldots, m+n \\
\sum_{i=1}^{m+n} a_{i}^{\prime}-P^{\prime} & \text { for } j=m+n+1\end{cases} \\
& c_{i j}^{\prime}=c_{i j} \quad \forall i, j=1,2, \ldots \ldots, m+n \\
& c_{i, m+n+1}^{\prime}=c_{m+n+1, j}^{\prime}=0 \quad \forall i, j=1,2, \ldots \ldots, m+n \\
& c_{m+n+1, m+n+1}^{\prime}=M \\
& y_{i j} \geq 0 \quad \forall i, j=1,2, \ldots \ldots \ldots, m+n+1
\end{aligned}
$$

Note4: We assign a cost zero to all the cells in the additional row and column except the $(m+n+1, m+n+1)$ th cell, where we assign a cost $M$, where $M$ is a large positive number.

Definition A basic feasible solution $\left\{\mathrm{y}_{\mathrm{ij}}\right\}, \mathrm{i}, \mathrm{j}=1,2, \ldots \ldots, \mathrm{m}+$ $\mathrm{n}+1$ to problem (P4) is called a corner feasible solution (cfs) if $\mathrm{y}_{\mathrm{m}+1, \mathrm{n}+1}=0$

Theorem1 Every corner feasible solution of (P4) provides a basic feasible solution to (P3) and conversely.

Proof : Let $\left\{\mathrm{y}_{\mathrm{ij}}\right\}$ be a cfs to (P4)

Define $\mathrm{x}_{\mathrm{ij}}=\mathrm{y}_{\mathrm{ij}},(\mathrm{i}, \mathrm{j}) \in \mathrm{I} \times \mathrm{J}$ where $\mathrm{I}, \mathrm{J}=\{1,2, \ldots ., \mathrm{m}+\mathrm{n}\}$

$\left\{\mathrm{x}_{\mathrm{ij}}\right\}$ so defined can be established to be a basic feasible solution to (P3).
Conversely, given $\left\{\mathrm{x}_{\mathrm{ij}}\right\}$ to be a basic feasible solution to (P3), then $\left\{y_{i j}\right\},(i, j) \in I^{\prime} \times J^{\prime}$

where $I^{\prime}, J^{\prime}=\{1,2, \ldots \ldots, m+n+1\}$ defined by the transformation

$$
\begin{array}{rlrl}
\mathrm{y}_{\mathrm{ij}} & =\mathrm{x}_{\mathrm{ij}},(\mathrm{i}, \mathrm{j}) \in \mathrm{I} \times \mathrm{J} & \\
y_{i, m+n+1} & =a_{i}^{\prime}-\sum_{j=1}^{m+n} x_{i j} & , i=1,2, \ldots \ldots, m \\
& =T-\sum_{j=1}^{m+n} x_{i j} & , i=m+1, \ldots ., m+n \\
y_{m+n+1, j} & =T-\sum_{i=1}^{m+n} x_{i j} & , j=1,2, \ldots, m+n \\
& =b_{j}^{\prime}-\sum_{i=1}^{m+n} x_{i j} & , j & \\
\mathrm{y}_{\mathrm{m}+\mathrm{n}+1, \mathrm{~m}+\mathrm{n}+1}=0 & &
\end{array}
$$

can be shown to be a cfs to (P4)

Theorem 2 The value of the objective function of (P4) at a corner feasible solution is equal to the value of the objective function of (P3) at its corresponding basic feasible solution.

Proof: Value of the objective function of $(\mathrm{P} 4)$ is

$$
\begin{aligned}
& =\sum_{\mathrm{i} \in \mathrm{I}^{\prime}} \sum_{\mathrm{j} \in \mathrm{J}^{\prime}} \mathrm{c}_{\mathrm{ij}}^{\prime} \mathrm{y}_{\mathrm{ij}} \\
& =\sum_{\mathrm{i} \in \mathrm{I}} \sum_{\mathrm{j} \in \mathrm{J}} \mathrm{c}_{\mathrm{ij}}^{\prime} \mathrm{y}_{\mathrm{ij}}+\sum_{j \in J^{\prime}} c_{m+n+1, j}^{\prime} y_{m+n+1, j}+\sum_{i \in I^{\prime}} c_{i, m+n+1}^{\prime} y_{i, m+n+1} \\
& =\sum_{i \in I} \sum_{j \in J} c_{i j} y_{i j} \quad\left(a s c_{m+n+1, j}^{\prime}=c_{i, m+n+1}^{\prime}=0, y_{m+n+1, m+n+1}=0\right) \\
& =\sum_{i \in I} \sum_{j \in J} c_{i j} x_{i j} \quad\left(\operatorname{sincex}_{\mathrm{ij}}=\mathrm{y}_{\mathrm{ij}},(\mathrm{i}, \mathrm{j}) \in \mathrm{I} \times \mathrm{J}\right) \\
& =\text { Value of the objective function of (P3) }
\end{aligned}
$$

Remark 2: A non-corner feasible solution to (P4) can not provide a feasible solution to $(\mathrm{P} 3)$

Theorem3 An optimal solution to (P4) has to be a corner feasible solution. 
Theorem4 There is a one to one correspondence between optimal solution to (P3) and optima among the corner feasible solutions to (P4).

Remark 3: Optimal corner feasible solution to $(\mathrm{P} 4)$ provides optimal solution to (P3).

Theorem 5 Optimizing (P3) is equivalent to optimizing (P4), provided (P3) has a feasible solution.

3.1 Algorithm to solve transshipment problem with impaired flow

Step1: Given the linear transshipment problem. If $\sum_{i=1}^{m} a_{i}=$ $\sum_{j=m+1}^{m+n} b_{j}$, then the transshipment problem is balanced, take $\mathrm{T}=\sum_{i=1}^{m} a_{i}$ else take $\mathrm{T}=\max \left(\sum_{i=1}^{m} a_{i}, \sum_{j=m+1}^{m+n} b_{j}\right)$ and go to step 2 .

Step2: Let the flow be impaired to $P^{\prime}$, where $P^{\prime}<\min$ $\left(\sum_{i=1}^{m} a_{i}+(m+n) T, \sum_{j=m+1}^{m+n} b_{j}+(m+n) T\right)$, Construct a transportation tableau as follows. A row in the tableau will be needed for each supply point and transshipment point, and a column will be needed for each demand point and transshipment point.

Step3: Add a dummy demand point/column with a demand $=$ $\left(\left(\sum_{i=1}^{m} a_{i}+(m+n) T\right)-P^{\prime}\right)$ or a dummy supply point/ row with a supply $=\left(\left(\sum_{j=m+1}^{m+n} b_{j}+(m+n) T\right)-P^{\prime}\right)$. Shipments to the dummy and from a point to itself are taken as zero.

Step4: Each transshipment point will have a supply equal to it's original supply $\left(a_{i}, i=1,2, \ldots, m\right)+T$ and will have a demand equal to its original demand $\left(b_{j}, j=m+1, m+2\right.$, $\ldots, m+n)+T$. Also, each supply point will have supply equal to original supply, $\mathrm{T}$ (for $\mathrm{i}=\mathrm{m}+1, \mathrm{~m}+2, \ldots \ldots, \mathrm{m}+$ n) and each demand point will have its demand equal to original demand, $\mathrm{T}$ (for $\mathrm{j}=1,2, \ldots \ldots, \mathrm{m}$ ). This ensures that any transshipment point that is a net supplier will have a net outflow equal to point's original supply and a net demander will have a net inflow equal to point's original demand. Although we don't know how much will be shipped through each transshipment point, we can be sure that the total amount will not exceed $\mathrm{T}$.

Step 5: Find out the optimal basic feasible solution of the transformed transportation problem (P4).

Step 6: Ignoring the allocations in the diagonal cells, the solution obtained is the optimal basic feasible solution for the transshipment problem (P3).

\section{Transshipment problem with enhanced flow}

Sometimes, situations may arise when because of the extra demand in the market, the total flow needs to be enhanced, compelling some of the factories to increase their productions in order to be able to meet this extra demand. Let $P^{\prime}>\max$ $\left(\sum_{i=1}^{m} a_{i}+(m+n) T, \sum_{j=m+1}^{m+n} b_{j}+(m+n) T\right)$ be the enhanced flow. The transshipment problem with enhanced flow is given by

Minimize $z=\sum_{i=1}^{m+n} \sum_{\substack{j=1 \\ j \neq i}}^{m+n} c_{i j} x_{i j}$

subject to

$\sum_{j=1}^{m+n} x_{i j} \geq a_{i}+T \quad \forall i=1,2, \ldots \ldots \ldots \ldots, m$

$\sum_{j=1}^{m+n} x_{i j}=T \quad \forall i=m+1, \ldots \ldots \ldots, m+n$

$\sum_{i=1}^{m+n} x_{i j}=T \quad \forall j=1,2, \ldots \ldots \ldots \ldots, m$

$\sum_{i=1}^{m+n} x_{i j} \geq b_{j}+T \quad \forall j=m+1, \ldots \ldots \ldots, m+n$

$\sum_{i=1}^{m+n} \sum_{j=1}^{m+n} x_{i j}=P^{\prime}\left(P^{\prime}>\max \left(\sum_{i=1}^{m} a_{i}+(m+n) T, \sum_{j=m+1}^{m+n} b_{j}+(m+n) T\right)\right)$

$x_{i j} \geq 0$

$\forall i, j=1,2, \ldots \ldots \ldots \ldots, m+n(i \neq j)$

$c_{i i}=0$

$\forall i=1,2, \ldots \ldots \ldots \ldots \ldots, m+n$

In order to deal with the flow constraint $\sum_{i=1}^{m+n m+n} \sum_{j=1}^{m} x_{i j}=P^{\prime}>$ $\max \left(\sum_{i=1}^{m} a_{i}+(m+n) T, \sum_{j=m+1}^{m+n} b_{j}+(m+n) T\right)$, a related transportation problem is formulated by adding an additional row with availability equal to $P^{\prime}-\left(\sum_{i=1}^{m} a_{i}+(m+n) T\right)$ and an additional column with demand equal to $P^{\prime}-\left(\sum_{j=m+1}^{m+n} b_{j}+(m+n) T\right)$. Hence the related transportation problem with enhanced flow is given as below. 
Minimize $z=\sum_{i=1}^{m+n+1} \sum_{j=1}^{m+n+1} c_{i j}^{\prime} y_{i j}$ subject to

$$
j \neq i
$$

$\sum_{j=1}^{m+n+1} y_{i j}=a_{i}^{\prime} \quad \forall i=1,2, \ldots \ldots, m+n, m+n+1$

$\sum_{i=1}^{m+n+1} y_{i j}=b_{j}^{\prime} \quad \forall j=1,2, \ldots \ldots, m+n, m+n+1$

$a_{i}^{\prime}= \begin{cases}a_{i}+T & \forall i=1, \ldots \ldots . ., m \\ T & \forall i=m+1, \ldots \ldots ., m+n \\ P^{\prime}-\sum_{i=1}^{m+n} a_{i}^{\prime} & \text { for } i=m+n+1\end{cases}$

$b_{j}^{\prime}= \begin{cases}T & \forall j=1, \ldots \ldots \ldots . ., m \\ b_{j}+T & \forall j=m+1, \ldots \ldots \ldots, m+n \\ P^{\prime}-\sum_{i=1}^{m+n} b_{j}^{\prime} & \text { for } j=m+n+1\end{cases}$

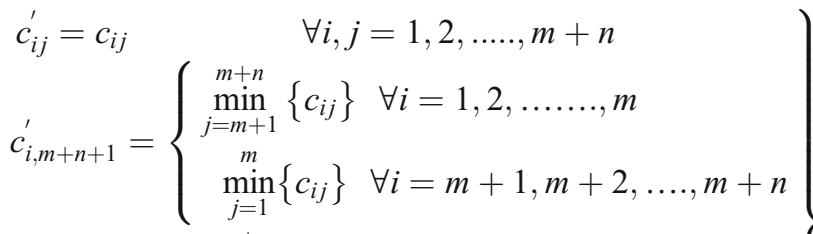

$c_{m+n+1, j}^{\prime}=\left\{\begin{array}{l}\min _{i=m+1}^{m+n}\left\{c_{i j}\right\} \quad \forall j=1,2, \ldots \ldots, m \\ \min _{i=1}^{m}\left\{c_{i j}\right\} \quad \forall j=m+1, m+2, \ldots, m+n\end{array}\right.$

$c_{m+n+1, m+n+1}^{\prime}=M$

$y_{i j} \geq 0 \quad \forall i, j=1,2, \ldots \ldots . ., m+n+1$

Note 5: We assign a cost $M$ to the $(m+n+1, m+n+1)$ th cell, where $\mathrm{M}$ is a large positive number and to absorb the additional flow, the rest of the elements in the additional row and column takes the minimum of the various cost as defined in (1).

4.1 Algorithm to solve transshipment problem with enhanced flow

Step1: Given the linear transshipment problem. If $\sum_{i=1}^{m} a_{i}=$ $\sum_{j=m+1}^{m+n} b_{j}$, then the transshipment problem is balanced, take $\mathrm{T}=\sum_{i=1}^{m} a_{i}$ else take $\mathrm{T}=\max \left(\sum_{i=1}^{m} a_{i}, \sum_{j=m+1}^{m+n} b_{j}\right)$ and go to step 2 .
Step2: Let the flow be restricted to $P^{\prime}$, where $P^{\prime}>\max$ $\left(\sum_{i=1}^{m} a_{i}+(m+n) T, \sum_{j=m+1}^{m+n} b_{j}+(m+n) T\right)$. Construct a transportation tableau as follows. A row in the tableau will be needed for each supply point and transshipment point, and a column will be needed for each demand point and transshipment point.

Step3: Add a dummy demand point/column with a demand $=$ $P^{\prime}-\left(\sum_{i=1}^{m} a_{i}+(m+n) T\right)$ or a dummy supply point/ row with a supply $=\left(P-\left(\sum_{j=m+1}^{m+n} b_{j}+(m+n) T\right)\right)$. Shipments from a point to itself are taken as zero.

Step 4: Assign a cost $M$ to the $(m+n+1, m+n+1)$ th cell, where $\mathrm{M}$ is a large positive number. The rest of the elements in the dummy row and column take the minimum of the various cost as defined in (1).

Step 5: Each transshipment point will have a supply equal to it's original supply $\left(\mathrm{a}_{\mathrm{i}}, \mathrm{i}=1,2, \ldots, \mathrm{m}\right)+\mathrm{T}$ and will have a demand equal to its original demand $\left(b_{j}, j=\right.$ $\mathrm{m}+1, \mathrm{~m}+2, \ldots, \mathrm{m}+\mathrm{n})+\mathrm{T}$. Also, each supply point will have supply equal to original supply, $\mathrm{T}$ (for $\mathrm{i}=$ $\mathrm{m}+1, \mathrm{~m}+2, \ldots ., \mathrm{m}+\mathrm{n})$ and each demand point will have its demand equal to original demand, $\mathrm{T}$ (for $\mathrm{j}=$ $1,2, \ldots \ldots, \mathrm{m})$.

Step 6: Find out the optimal basic feasible solution of the transformed transportation problem (P6).

Step 7: Ignoring the allocations in the diagonal cells, the solution obtained is the optimal basic feasible solution for the transshipment problem (P5).

\section{Unbalanced capacitated transshipment problem}

If in a given problem, the total availability $\sum_{i=1}^{m+n} a_{i}$ is not equal to the total demand $\sum_{j=1}^{m+n} b_{j}$, then some of the source and/or destination constraints are satisfied as inequalities. This gives rise to an unbalanced capacitated transshipment problem (UCTsP) whose related balanced capacitated transportation problem is given below.

$\operatorname{Minimize} \sum_{i=1}^{m+n} \sum_{j=1}^{m+n} c_{i j} x_{i j}$ 
subject to

$$
\begin{aligned}
& \sum_{j=1}^{m+n} x_{i j}=a_{i}+T \quad \forall i=1,2, \ldots \ldots \ldots \ldots, m \\
& \sum_{j=1}^{m+n} x_{i j}=T \\
& \sum_{i=1}^{m+n} x_{i j}=T \\
& \forall i=m+1, \ldots \ldots \ldots . ., m+n \\
& \sum_{i=1}^{m+n} x_{i j}=b_{j}+T \quad \forall j=m+1, \ldots \ldots \ldots, m+n \\
& c_{i i}=0 \\
& \forall i=1,2, \ldots \ldots \ldots \ldots . ., m+n \\
& x_{i j} \geq 0 \\
& \forall i, j=1,2, \ldots \ldots \ldots \ldots, m+n
\end{aligned}
$$

Depending upon the situation, there exist various cases for UCTsP. In the next section, we discuss the various cases of UCTsP.

Case I: Sometimes situations are arise when one wishes to keep stocks at the sources for emergencies and/or over supply to destinations due to high storage cost at some sources. This gives rise to the following UCTP

Minimize $\sum_{i=1}^{m+n} \sum_{j=1}^{m+n} c_{i j} x_{i j}$

subject to

$$
\begin{array}{ll}
\sum_{j=1}^{m+n} x_{i j} \leq a_{i}+T & \forall i=1,2, \ldots \ldots \ldots \ldots, m \\
\sum_{j=1}^{m+n} x_{i j}=T & \forall i=m+1, \ldots \ldots \ldots, m+n \\
\sum_{i=1}^{m+n} x_{i j}=T & \forall j=1,2, \ldots \ldots \ldots \ldots, m \\
\sum_{i=1}^{m+n} x_{i j} \geq b_{j}+T & \forall j=m+1, \ldots \ldots \ldots, m+n \\
x_{i j} \geq 0 & \forall i, j=1,2, \ldots \ldots \ldots \ldots, m+n \\
c_{i i}=0 & \forall i=1,2, \ldots \ldots \ldots \ldots ., m+n
\end{array}
$$

Problem (P8) can be solved by solving the following transportation problem

$\operatorname{Minimize} \sum_{i=1}^{m+n} \sum_{j=1}^{m+n+1} c_{i j}^{\prime} x_{i j}$ subject to

$$
\begin{array}{ll}
\sum_{j=1}^{m+n+1} x_{i j}=a_{i}^{\prime} & \forall i=1,2, \ldots \ldots \ldots ., m+n \\
\sum_{i=1}^{m+n} x_{i j}=b_{j}^{\prime} & \forall j=1,2, \ldots \ldots, m+n, m+n+1 \\
x_{i j} \geq 0 & \forall i=1,2, \ldots . ., m+n ; j=1,2, \ldots, m+n+1
\end{array}
$$

where

$$
\begin{aligned}
& a_{i}^{\prime}= \begin{cases}a_{i}+T & \forall i=1, \ldots \ldots \ldots, m \\
T & \forall i=m+1, \ldots \ldots \ldots, m+n\end{cases} \\
& b_{i}^{\prime}=\left\{\begin{array}{l}
T \quad \forall \quad j=1, \ldots \ldots \ldots, m \\
b_{j}+T \quad \forall j=m+1, \ldots \ldots \ldots, m+n \\
\sum_{i=1}^{\forall} a_{i}-\sum_{j=m+1}^{m+n} b_{j}, j=m+n+1
\end{array}\right. \\
& c_{i m+n+1}^{\prime}=0 \quad \forall i=1,2, \ldots \ldots \ldots . ., m+n \\
& c_{i j}^{\prime}=c_{i j} \quad \forall i, j=1,2, \ldots \ldots \ldots, m+n \\
& c_{i i}^{\prime}=0 \quad \forall i=1,2, \ldots \ldots \ldots \ldots . ., m+n
\end{aligned}
$$

which is of the form (P2).

In another situation, when total availability of material at sources is less than total demand at various destinations then over production at sources may be required and still some destinations may be short supplied. Thus the problem is of the form

Minimize $\sum_{i=1}^{m+n} \sum_{j=1}^{m+n} c_{i j} x_{i j}$

subject to

$\sum_{j=1}^{m+n} x_{i j} \geq a_{i}+T \quad \forall i=1,2, \ldots \ldots \ldots \ldots, m$

$\sum_{j=1}^{m+n} x_{i j}=T \quad \forall i=m+1, \ldots \ldots \ldots, m+n$

$\sum_{i=1}^{m+n} x_{i j}=T \quad \forall j=1,2, \ldots \ldots \ldots \ldots, m$

$$
\begin{array}{ll}
\sum_{i=1}^{m+n} x_{i j} \leq b_{j}+T & \forall j=m+1, \ldots \ldots \ldots, m+n \\
x_{i j} \geq 0 & \forall i, j=1,2, \ldots \ldots \ldots, m+n
\end{array}
$$

This problem can also be reduced to the form (P2) as follows 
$\operatorname{Minimize} \sum_{i=1}^{m+n+1} \sum_{j=1}^{m+n} c_{i j}^{\prime} x_{i j}$

subject to

$\sum_{j=1}^{m+n} x_{i j}=a_{i}^{\prime} \quad \forall i=1,2, \ldots \ldots \ldots, m+n+1$

$\sum_{i=1}^{m+n+1} x_{i j}=b_{i}^{\prime} \quad \forall j=1,2, \ldots \ldots \ldots ., m+n$

$x_{i j} \geq 0 \quad \forall i=1,2, \ldots \ldots, m+n+1 ; j=1,2, \ldots, m+n$

where

$a_{i}^{\prime}= \begin{cases}a_{i}+T & \forall i=1, \ldots \ldots \ldots, m \\ T & \forall i=m+1, \ldots \ldots \ldots, m+n \\ \sum_{j=m+1}^{m+n} b_{j}-\sum_{i=1}^{m} a_{i}, \quad i=m+n+1\end{cases}$

$b_{j}^{\prime}= \begin{cases}T & \forall j=1, \ldots \ldots \ldots, m \\ b_{j}+T & \forall j=m+1, \ldots \ldots \ldots, m+n\end{cases}$

$c^{\prime}{ }_{m+n+1 j}=0 \quad \forall i=1,2, \ldots \ldots \ldots \ldots, m+n$

$c^{\prime}{ }_{i j}=c_{i j} \quad \forall i, j=1,2, \ldots \ldots \ldots, m+n$

$c^{\prime}{ }_{i i}=0 \quad \forall i=1,2, \ldots \ldots \ldots \ldots, m+n$

which can be solved easily.

Also, problem (P9) with flow constraint can also be reduced to the problem of the form (P3).

Case II: When the total availability at the sources is less than the total requirement at the destinations and one has to satisfy the exact demand at all the destinations by over producing at sources, then the problem takes the following form:

Minimize $\sum_{i=1}^{m+n} \sum_{j=1}^{m+n} c_{i j} x_{i j}$ subject to

$$
\begin{array}{ll}
\sum_{j=1}^{m+n} x_{i j} \geq a_{i}+T & \forall i=1,2, \ldots \ldots \ldots \ldots, m \\
\sum_{j=1}^{m+n} x_{i j}=T & \forall i=m+1, \ldots \ldots \ldots, m+n \\
\sum_{i=1}^{m+n} x_{i j}=T & \forall j=1,2, \ldots \ldots \ldots \ldots, m \\
\sum_{i=1}^{m+n} x_{i j}=b_{j}+T & \forall j=m+1, \ldots \ldots \ldots, m+n \\
x_{i j} \geq 0 & \forall i, j=1,2, \ldots \ldots \ldots, m+n
\end{array}
$$

This problem can be easily reduced to the form of problem (P11) and can be solved.

Similarly, consider the case where the problem is of the following form

Minimize $\sum_{i=1}^{m+n} \sum_{j=1}^{m+n} c_{i j} x_{i j}$

subject to

$$
\begin{array}{ll}
\sum_{j=1}^{m+n} x_{i j}=a_{i}+T & \forall i=1,2, \ldots \ldots \ldots \ldots, m \\
\sum_{j=1}^{m+n} x_{i j}=T & \forall i=m+1, \ldots \ldots \ldots, m+n \\
\sum_{i=1}^{m+n} x_{i j}=T & \forall j=1,2, \ldots \ldots \ldots \ldots, m \\
\sum_{i=1}^{m+n} x_{i j} \geq b_{j}+T & \forall j=m+1, \ldots \ldots \ldots, m+n \\
& \\
x_{i j} \geq 0 & \forall i, j=1,2, \ldots \ldots \ldots, m+n
\end{array}
$$

Here, total availability is greater than total requirement, no storage is allowed at sources and over supply to destinations is allowed, can be solved by reducing it to the form (P9).

Case III: Certain situations, where storage is allowed at sources and demands are to be exactly met at 
destinations give rise to UCTP of the form:

Minimize $\sum_{i=1}^{m+n} \sum_{j=1}^{m+n} c_{i j} x_{i j}$

subject to

$$
\begin{array}{ll}
\sum_{j=1}^{m+n} x_{i j} \leq a_{i}+T & \forall i=1,2, \ldots \ldots \ldots \ldots, m \\
\sum_{j=1}^{m+n} x_{i j}=T & \forall i=m+1, \ldots \ldots \ldots, m+n \\
\sum_{i=1}^{m+n} x_{i j}=T & \forall j=1,2, \ldots \ldots \ldots \ldots, m \\
\sum_{i=1}^{m+n} x_{i j}=b_{j}+T & \forall j=m+1, \ldots \ldots \ldots, m+n \\
x_{i j} \geq 0 & \forall i, j=1,2, \ldots \ldots \ldots \ldots . ., m+n \\
c_{i i}=0 & \forall i=1,2, \ldots \ldots \ldots \ldots ., m+n
\end{array}
$$

This problem (P14) can be solved by adding only an additional column where the variables in the additional column represent the stored amount at the sources. Here the problem reduces to the form (P9) and hence can be solved easily.

The problem where exact amount to be supplied, short supply is allowed at destinations and the constraints are of the form

Minimize $\sum_{i=1}^{m+n} \sum_{j=1}^{m+n} c_{i j} x_{i j}$

subject to

$$
\begin{array}{ll}
\sum_{j=1}^{m+n} x_{i j}=a_{i}+T & \forall i=1,2, \ldots \ldots \ldots \ldots, m \\
\sum_{j=1}^{m+n} x_{i j}=T & \forall i=m+1, \ldots \ldots \ldots, m+n \\
\sum_{i=1}^{m+n} x_{i j}=T & \forall j=1,2, \ldots \ldots \ldots \ldots, m \\
\sum_{i=1}^{m+n} x_{i j} \leq b_{j}+T & \forall j=m+1, \ldots \ldots \ldots, m+n \\
x_{i j} \geq 0 & \forall i=1,2, \ldots \ldots \ldots \ldots, m+n \\
c_{i i}=0 & \forall i=1,2, \ldots \ldots \ldots \ldots, m+n
\end{array}
$$

can be similarly solved by reducing it into the form of problem (P11).
5.1 Algorithm for unbalanced capacitated transhipment problem

Step 1: Given the unbalanced transshipment problems of the forms P8, P10, P12, P13, P14 and P15, transform them into their respective transportation problems P9, P11, P11, P9, P9 and P11.

Step 2: Problem P9 and problem P11 are of the form of problem P2 whose optimal basic feasible solution can be obtained as explained in Section 2.

\section{Numerical examples}

Example1. Transshipment problem with impaired flow Consider the following Unbalanced Transshipment problem (P16) involving two origins and two destinations. The availabilities at the origins, the requirements at the destinations and the costs of transportation are given in Table 1 below.

Since $\sum_{j=3}^{4} b_{j}>\sum_{i=1}^{2} a_{i}$ we take buffer stock, $T=\max$ $\left(\sum_{i=1}^{2} a_{i}, \sum_{j=3}^{4} b_{j}\right)=9$ and convert the problem into a balanced transshipment problem by adding 9 units to each $a_{i}$ and $b_{j} ; i, j=1$, $2,3,4$. The transformed transportation problem is given in Table 2 .

Let $P^{\prime}$ be the total flow, restricted to 40 .

Table 1 (Cost matrix of unbalanced transshipment problem (P16))

\begin{tabular}{llllll}
\hline $\mathbf{i} \mathbf{j} \rightarrow$ & $\mathrm{O}_{1}$ & $\mathrm{O}_{2}$ & $\mathrm{D}_{1}$ & $\mathrm{D}_{2}$ & $\mathrm{a}_{\mathrm{j}}$ \\
$\downarrow$ & & & & & \\
\hline $\mathrm{O}_{1}$ & 0 & 1 & 5 & 4 & 3 \\
$\mathrm{O}_{2}$ & 1 & 0 & 2 & 6 & 4 \\
$\mathrm{D}_{1}$ & 5 & 2 & 0 & 2 & - \\
$\mathrm{D}_{2}$ & 4 & 6 & 2 & 0 & - \\
$\mathrm{b}_{\mathrm{j}}$ & - & - & 6 & 3 & \\
\hline
\end{tabular}

Table 2 (Transformed transportation problem)

\begin{tabular}{lllrrr}
\hline $\mathbf{i} \mathbf{j} \rightarrow$ & $\mathrm{O}_{1}$ & $\mathrm{O}_{2}$ & $\mathrm{D}_{1}$ & $\mathrm{D}_{2}$ & $\mathrm{a}_{\mathrm{i}}$ \\
$\downarrow$ & & & & & \\
\hline $\mathrm{O}_{1}$ & 0 & 1 & 5 & 4 & 12 \\
$\mathrm{O}_{2}$ & 1 & 0 & 2 & 6 & 13 \\
$\mathrm{D}_{1}$ & 5 & 2 & 0 & 2 & 9 \\
$\mathrm{D}_{2}$ & 4 & 6 & 2 & 0 & 9 \\
$\mathrm{dO}_{3}$ & 0 & 0 & 0 & 0 & 2 \\
$\mathrm{~b}_{\mathrm{j}}$ & 9 & 9 & 15 & 12 & \\
\hline
\end{tabular}


Table 3 Optimal solution of transformed transportation problem with impaired flow

\begin{tabular}{lllllll}
\hline $\mathbf{i} \mathbf{j} \rightarrow$ & $\mathrm{O}_{1}$ & $\mathrm{O}_{2}$ & $\mathrm{D}_{1}$ & $\mathrm{D}_{2}$ & $\mathrm{dO}_{3}$ & $\mathrm{a}_{\mathrm{i}}$ \\
$\mathbf{\downarrow}$ & & & & & & \\
\hline $\mathrm{O}_{1}$ & $0(9)$ & 1 & 5 & 4 & $0(3)$ & 12 \\
$\mathrm{O}_{2}$ & 1 & $0(9)$ & $2(4)$ & 6 & 0 & 13 \\
$\mathrm{D}_{1}$ & 5 & 2 & $0(9)$ & 2 & 0 & 9 \\
$\mathrm{D}_{2}$ & 4 & 6 & 2 & $0(9)$ & 0 & 9 \\
$\mathrm{dO}_{3}$ & 0 & 0 & $0(2)$ & $0(3)$ & $\mathrm{M}$ & 5 \\
$\mathrm{~b}_{\mathrm{j}}$ & 9 & 9 & 15 & 12 & 3 & \\
\hline
\end{tabular}

Here we add a dummy row $\mathrm{dO}_{3}$ and a dummy column $\mathrm{dO}_{3}$ with each cell having a cost 0 except $\mathrm{c}_{55}$ having cost $\mathrm{M}$. And we take demand $=\sum_{i=1}^{4} a_{i}-P^{\prime}=43-40=3$ and supply $=$ $\sum_{j=1}^{4} b_{j}-P^{\prime}=45-40=5$.

Next we find out the initial basic feasible solution by any of the regular method and check its optimality. The optimal solution is given in the Table 3 below.

Ignoring the allocations in the diagonal cells, we obtain the optimal basic feasible solution for the transshipment problem with impaired flow. The optimal schedule is $\mathrm{O}_{1}-\mathrm{dO}_{3}$, 3 units; $\mathrm{O}_{2}-\mathrm{D}_{1}, 4$ units; $\mathrm{O}_{3}-\mathrm{D}_{1}, 2$ units; $\mathrm{dO}_{3}-\mathrm{D}_{2}$, 3units or we can say $x_{15}=3, x_{23}=4, x_{53}=2, x_{54}=3$ with $\min Z=8$.

The optimal schedule of the transhipment problem with impaired flow is described in the flow chart (Fig. 1)

In the Fig. 1, the allocations in the diagonal cells are ignored, since they do not have any physical meaning i.e., no transportation. The remaining allocations are summarized as follows.

(a) O1 transports 3 units to the dummy point source/ destination, so the supply capacity of $\mathrm{dO} 3$ increases to 5 units including the original availability of 2 units.

(b) Of the 5 units supply capacity of dO3, dO3 transport 2 units to D1 and 3 units to D2

(c) $\mathrm{O} 2$ transports 4 units to D1.

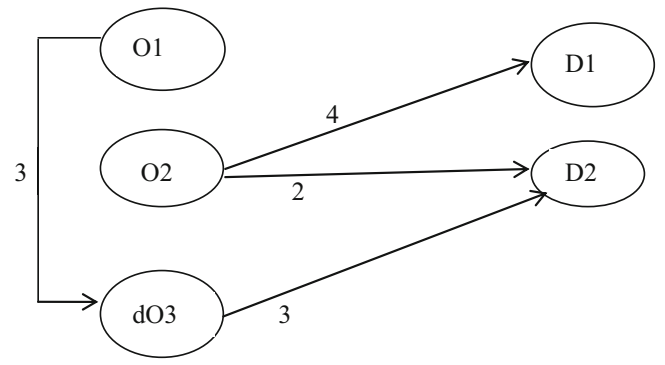

Fig. 1 Impaired flow
Thus the original demand of 6 units of $\mathrm{D} 1$ and 3 units of $\mathrm{D} 2$ are satisfied.

Example2. Transshipment problem with enhanced flow Consider the same Unbalanced Transshipment Problem (P16) and its transformed transportation problem with flow, $P^{\prime}$, enhanced to 48 .

Here we add a dummy column $\mathrm{dO}_{3}$ with supply $=P^{\prime}-$ $\sum_{i=1}^{4} a_{i}=48-43=5$ and a dummy row $\mathrm{dO}_{3}$ with demand $=$ $P^{\prime}-\sum_{j=1}^{4} b_{j}=48-45=3$.

Also, $c_{15}=4, c_{25}=2, c_{35}=2, c_{45}=4 ; c_{51}=4, c_{52}=2, c_{53}=2$, $c_{54}=4 ; c_{55}=\mathrm{M}$.

Next we find out the initial basic feasible solution by any of the method and check its optimality. The optimal solution is given in the Table 4 below.

The optimal schedule for the above unbalanced transshipment problem with enhanced flow is $\mathrm{O}_{1}-\mathrm{D}_{2}$, 3units; $\mathrm{O}_{2} \longrightarrow \mathrm{D}_{1}, 1$ unit; $\mathrm{O}_{2}-\mathrm{dO}_{3}, 3$ units; $\mathrm{dO}_{3}-\mathrm{D}_{1}$, 5units or we can say $\mathrm{x}_{14}=3, \mathrm{x}_{23}=1, \mathrm{x}_{25}=3, \mathrm{x}_{53}=5$ with min $\mathrm{Z}=30$.

The optimal schedule of the transhipment problem with enhanced flow is described in the flow chart (Fig. 2).

In the Fig. 2, the allocations in the diagonal cells are ignored, since they do not have any physical meaning i.e., no transportation. The remaining allocations are summarized as follows.

(a) O1 transports 3 units to the D2

(b) $\mathrm{O} 2$ transports 3 units to the dummy point so the supply capacity of dO3 increases to 5 units including the original supply of 2 units.

(c) $\mathrm{O} 2$ transports 1 unit to $\mathrm{D} 1$ and $\mathrm{dO} 3$ transports 5 units to D1.

Thus the original demand of 6 units of D1 and 3 units of D2 are satisfied.

Table 4 Optimal solution of transformed transportation problem with enhanced flow

\begin{tabular}{lrrrrrr}
\hline $\mathbf{i} \mathbf{j} \rightarrow$ & $\mathrm{O}_{1}$ & \multicolumn{1}{c}{$\mathrm{O}_{2}$} & \multicolumn{1}{c}{$\mathrm{D}_{1}$} & \multicolumn{1}{c}{$\mathrm{D}_{2}$} & $\mathrm{dO}_{3}$ & $\mathrm{a}_{\mathrm{i}}$ \\
$\mathbf{v}$ & & & & & & \\
\hline $\mathrm{O}_{1}$ & $0(9)$ & 1 & 5 & $4(3)$ & 4 & 12 \\
$\mathrm{O}_{2}$ & 1 & $0(9)$ & $2(1)$ & 6 & $2(3)$ & 13 \\
$\mathrm{D}_{1}$ & 5 & 2 & $0(9)$ & 2 & 2 & 9 \\
$\mathrm{D}_{2}$ & 4 & 6 & 2 & $0(9)$ & 4 & 9 \\
$\mathrm{dO}_{3}$ & 4 & 2 & $2(5)$ & 4 & $\mathrm{M}$ & 5 \\
$\mathrm{~b}_{\mathrm{j}}$ & 9 & 9 & 15 & 12 & 3 & \\
\hline
\end{tabular}




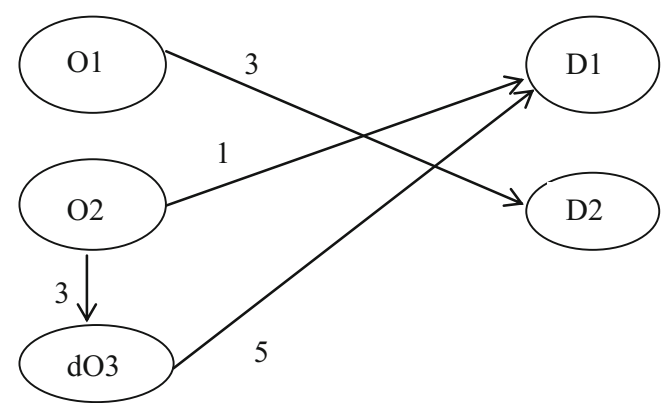

Fig. 2 Enhanced flow

\section{Computational results}

We also solved various test problems for higher dimensions with different scenarios by varying the number of nodes, the demand and other parameters on GAMS (General Algebraic Modeling System) on a PC with Intel Pentium Processor $1.40 \mathrm{GHz}$ having $1.25 \mathrm{~GB}$ RAM and it took less than $5 \mathrm{~s}$ to solve the problems.

We have solved transshipment problems of order $2 \times 2$ for Case-I, II, III, impaired and enhanced flow and of order $5 \times 5$ for impaired and enhanced flow. The cost matrices of the test problems are given in Tables 5 and 6. The input data of availability, demand etc. and the optimal basic feasible solutions of the test problems are provided in Tables 7 and 8 respectively.

Ignoring the allocations in the diagonal cells, the optimal schedule for various test problems is described in the flow charts below (Figs. 3 to 14). The author has explained the meaning of $5 \times 5$ problems described in Figs. 7 and 8 . The rest of flow charts can be understood in the same way.

The allocations in Fig. 7 are summarized as follows.

(a) O1 has availability of 10 units which is transported to dummy point source/destination, so that supply capacity of $\mathrm{dO} 3$ increases to 18 units including the original availability of 8

Table 5 Cost matrix for Case-I, II, III, impaired and enhanced flow transshipment problem with 2 origins and 2 destinations

\begin{tabular}{lllll}
\hline $\mathbf{i} \mathbf{j} \rightarrow$ & $\mathrm{O}_{1}$ & $\mathrm{O}_{2}$ & $\mathrm{D}_{1}$ & $\mathrm{D}_{2}$ \\
$\downarrow$ & & & & \\
\hline $\mathrm{O}_{1}$ & 0 & 1 & 5 & 4 \\
$\mathrm{O}_{2}$ & 1 & 0 & 2 & 6 \\
$\mathrm{D}_{1}$ & 5 & 2 & 0 & 2 \\
$\mathrm{D}_{2}$ & 4 & 6 & 2 & 0 \\
\hline
\end{tabular}

Table 6 Cost matrix for the impaired and enhanced flow transshipment problem with 5 origins and 5 destinations

\begin{tabular}{|c|c|c|c|c|c|c|c|c|c|c|}
\hline $\begin{array}{l}\mathbf{i} \mathbf{j} \rightarrow \\
\downarrow\end{array}$ & $\mathrm{O}_{1}$ & $\mathrm{O}_{2}$ & $\mathrm{O}_{3}$ & $\mathrm{O}_{4}$ & $\mathrm{O}_{5}$ & $\mathrm{D}_{1}$ & $\mathrm{D}_{2}$ & $\mathrm{D}_{3}$ & $\mathrm{D}_{4}$ & $\mathrm{D}_{5}$ \\
\hline $\mathrm{O}_{1}$ & 0 & 1 & 2 & 3 & 4 & 7 & 6 & 5 & 4 & 3 \\
\hline $\mathrm{O}_{2}$ & 1 & 0 & 1 & 2 & 3 & 6 & 5 & 4 & 3 & 2 \\
\hline $\mathrm{O}_{3}$ & 2 & 1 & 0 & 1 & 2 & 4 & 3 & 2 & 1 & 2 \\
\hline $\mathrm{O}_{4}$ & 3 & 2 & 1 & 0 & 1 & 8 & 7 & 4 & 3 & 6 \\
\hline $\mathrm{O}_{5}$ & 4 & 3 & 2 & 1 & 0 & 2 & 1 & 3 & 4 & 2 \\
\hline $\mathrm{D}_{1}$ & 7 & 6 & 4 & 8 & 2 & 0 & 4 & 3 & 2 & 1 \\
\hline $\mathrm{D}_{2}$ & 6 & 5 & 3 & 7 & 1 & 4 & 0 & 4 & 3 & 2 \\
\hline $\mathrm{D}_{3}$ & 5 & 4 & 2 & 4 & 3 & 3 & 4 & 0 & 4 & 3 \\
\hline $\mathrm{D}_{4}$ & 4 & 3 & 1 & 3 & 4 & 2 & 3 & 4 & 0 & 4 \\
\hline $\mathrm{D}_{5}$ & 3 & 2 & 2 & 6 & 2 & 1 & 2 & 3 & 4 & 0 \\
\hline
\end{tabular}

units (total supply being 50 units minus total demand being 42 units) at dummy point source/ destination

(b) Of the 18 units supply capacity of dO3, 2 units are transported from $\mathrm{dO} 3$ to $\mathrm{D} 1$.

(c) Of the 12 units available at $\mathrm{O} 2,8$ units are transported to $\mathrm{O} 3$ which increases the supply capacity of $\mathrm{O} 3$ to 13 units including the original availability of 5 units, and 4 units are transported to D5.

(d) O4 has availability of 15 units out of which 6 units are transported to $\mathrm{O} 3$ which increases the supply capacity to $\mathrm{O} 3$ to 19 units (as from (c) $\mathrm{O} 3$ had 13 units), and 9 units are transported to $\mathrm{O} 5$ which increases the supply capacity to O5 to 17 units including the original availability of 8 units.

(e) Of the 19 units supply capacity of O3 from (d), 9 units are transported to D3 and 10 units to D4.

(f) Of the 17 units supply capacity of O5 from (d), 6 units are transported to D1 and 11 units are transported to D2.

(g) D1 receives 6 units from $\mathrm{O} 5$ and 2 units from $\mathrm{dO} 3$ which satisfies the requirement of D1.

(h) D2 receives 11 units from $\mathrm{O}$, D3 receives 9 units from $\mathrm{O} 3$, D4 receives 10 units from $\mathrm{O} 3$ and $\mathrm{D} 5$ receives 4 units $\mathrm{O} 2$ which satisfies their respective original requirements.

The allocations in Fig. 8 are summarized as follows.

(a) $\mathrm{O} 1$ has availability of 10 units which is transported $\mathrm{O} 2$ which increases the supply capacity of $\mathrm{O} 2$ to 22 units, including its original availability of 12 units.

(b) Of the 22 units supply capacity of O2 (as from (a)), 4 units are transported to D5 and 18 units are transported to $\mathrm{O} 3$ which increases the supply capacity of $\mathrm{O} 3$ to 23 units, including its original availability of 5 units. 
Table 7 Input data of various test problems

\begin{tabular}{|c|c|c|c|c|c|c|}
\hline \multirow{2}{*}{$\begin{array}{l}\text { Test problem } \\
\text { no. }\end{array}$} & \multirow[t]{2}{*}{ Problem no./type } & \multicolumn{2}{|l|}{ Order of } & \multirow{2}{*}{$\begin{array}{l}\text { Original availability } \\
\text { and demand of the } \\
\text { transshipment problem }\end{array}$} & \multirow{2}{*}{$\begin{array}{l}\text { Buffer } \\
\text { stock (T) }\end{array}$} & \multirow{2}{*}{$\begin{array}{l}\text { Availability and demand of the } \\
\text { transformed transportation } \\
\text { problem with dummy point } \\
\text { source/destination }\end{array}$} \\
\hline & & $\begin{array}{l}\text { Original } \\
\text { transshipment } \\
\text { problem }\end{array}$ & $\begin{array}{l}\text { Transformed } \\
\text { transportation } \\
\text { problem }\end{array}$ & & & \\
\hline 7.2 & $\begin{array}{l}\text { Impaired Flow (P4) } \\
\quad P^{\prime}=40 \\
\text { Enhanced Flow (P6) } \\
\quad P^{\prime}=48\end{array}$ & $2 \times 2$ & $5 \times 5$ & $a_{1}=4, a_{2}=5, b_{3}=3, b_{4}=6$ & 9 & $\begin{array}{l}a_{1}=13, a_{2}=14, a_{3}=9, a_{4}=9, \\
\quad b_{1}=9, b_{2}=9, b_{3}=12, b_{4}=15, \\
a_{5}=5, b_{6}=5\end{array}$ \\
\hline 7.4 & $\begin{array}{l}\text { Impaired Flow (P4) } \\
\quad P^{\prime}=115 \\
\text { Enhanced Flow (P6) } \\
\quad P^{\prime}=130\end{array}$ & $2 \times 2$ & $5 \times 5$ & $a_{1}=8, a_{2}=12, b_{3}=15, b_{4}=10$ & 25 & $\begin{array}{l}a_{1}=33, a_{2}=37, a_{3}=25, a_{4}=25, \\
\quad b_{1}=25, b_{2}=25, b_{3}=40, b_{4}=35, \\
\quad a_{5}=10, b_{6}=5\end{array}$ \\
\hline 7.5 & $\begin{array}{l}\text { Impaired Flow (P4) } \\
\quad P^{\prime}=540\end{array}$ & $5 \times 5$ & $11 \times 11$ & $\begin{array}{l}a_{1}=10, a_{2}=12, a_{3}=5, \\
a_{4}=15, a_{5}=8, b_{6}=8, \\
b_{7}=11, b_{8}=9, b_{9}=10, \\
b_{10}=4\end{array}$ & 50 & $\begin{array}{c}a_{1}=60, a_{2}=62, a_{3}=55, a_{4}=65, \\
a_{5}=58, a_{6}=50, a_{7}=50, a_{8}=50, \\
a_{9}=50, a_{10}=50, b_{1}=50, b_{2}=50, \\
b_{3}=50, b_{4}=50, b_{5}=50, b_{6}=58, \\
b_{7}=61, b_{8}=59, b_{9}=60, b_{10}=54, \\
a_{11}=2, b_{11}=10\end{array}$ \\
\hline 7.6 & $\begin{array}{l}\text { Enhanced Flow (P6) } \\
\quad P^{\prime}=555\end{array}$ & & & & & $\begin{array}{l}\text { All values are same as impaired } \\
\text { flow except dummy points } \\
a_{11}=5, b_{11}=13\end{array}$ \\
\hline 7.7 & $\begin{array}{l}\text { Case-I } \\
(\mathrm{P} 8)\end{array}$ & $2 \times 2$ & $4 \times 5$ & $a_{1}=7, a_{2}=5, b_{3}=3, b_{4}=6$ & 12 & $\begin{array}{l}a_{1}=19, a_{2}=17, a_{3}=12, a_{4}=12, \\
\quad b_{1}=12, b_{2}=12, b_{3}=15, b_{4}=18, \\
\quad b_{5}=3\end{array}$ \\
\hline 7.8 & (P10) & $2 \times 2$ & $5 \times 4$ & $a_{1}=4, a_{2}=5, b_{3}=8, b_{4}=6$ & 14 & $\begin{array}{l}a_{1}=18, a_{2}=19, a_{3}=14, a_{4}=14, \\
\quad b_{1}=14, b_{2}=14, b_{3}=22, b_{4}=20, \\
\quad a_{5}=5\end{array}$ \\
\hline 7.9 & $\begin{array}{l}\text { Case-II } \\
(\mathrm{P} 12)\end{array}$ & $2 \times 2$ & $5 \times 4$ & $a_{1}=4, a_{2}=5, b_{3}=7, b_{4}=10$ & 17 & $\begin{array}{l}a_{1}=21, a_{2}=22, a_{3}=17, a_{4}=17, \\
\quad b_{1}=17, b_{2}=17, b_{3}=24, b_{4}=27, \\
\quad a_{5}=8\end{array}$ \\
\hline 7.10 & (P13) & $2 \times 2$ & $4 \times 5$ & $a_{1}=8, a_{2}=7, b_{3}=3, b_{4}=6$ & 15 & $\begin{array}{l}a_{1}=23, a_{2}=22, a_{3}=15, a_{4}=15, \\
\quad b_{1}=15, b_{2}=15, b_{3}=18, b_{4}=21, \\
\quad b_{5}=6\end{array}$ \\
\hline 7.11 & $\begin{array}{l}\text { Case-III } \\
(\mathrm{P} 14)\end{array}$ & $2 \times 2$ & $4 \times 5$ & $a_{1}=8, a_{2}=12, b_{3}=4, b_{4}=7$ & 20 & $\begin{array}{l}a_{1}=28, a_{2}=32, a_{3}=20, a_{4}=20, \\
\quad b_{1}=20, b_{2}=20, b_{3}=24, b_{4}=27, \\
\quad b_{5}=9\end{array}$ \\
\hline 7.12 & (P15) & $2 \times 2$ & $5 \times 4$ & $\begin{array}{l}a_{1}=4, a_{2}=10, b_{3}=10 \\
\quad b_{4}=15\end{array}$ & 25 & $\begin{array}{l}a_{1}=29, a_{2}=35, a_{3}=25, a_{4}=25, \\
\quad b_{1}=25, b_{2}=25, b_{3}=35, b_{4}=40, \\
\quad a_{5}=11\end{array}$ \\
\hline
\end{tabular}

(c) $\mathrm{O} 4$ has availability of 15 units out of 9 units are transported to $\mathrm{O} 3$ which increases the supply capacity of $\mathrm{O} 3$ to 32 units (as from (b) $\mathrm{O} 3$ had 23 units) and 6 units are transported to $\mathrm{O} 5$ which increases the supply capacity of $\mathrm{O} 5$ to 14 units, including the original availability of 8 units.

(d) Of the 32 units available at $\mathrm{O} 3$ from (c), 9 units are transported to D3, 10 units are transported to D4 and 13 units are transported to $\mathrm{dO} 3$ which increases the supply capacity of dummy supply point source/ destination to 21 units, including the original availability of 8 units (total supply being 50 units minus total demand being 42 units) at dummy point source/ destination.

(e) Of the 14 units available at O5 from (c), 3 units are transported to D1 and 11 units to D2.

(f) D1 receives 3 units from $\mathrm{O} 5$ and 5 units from $\mathrm{dO} 3$ which satisfies the original requirement of D1.

(g) D2 receives 11 units from O5, D3 receives 9 units from $\mathrm{O} 3$, D4 receives 10 units from $\mathrm{O} 3$ and $\mathrm{D} 5$ receives 4 units $\mathrm{O} 2$ which satisfies their respective original requirements. 
Table 8 Optimal basic feasible solution of various test problems

\begin{tabular}{|c|c|c|c|c|}
\hline $\begin{array}{l}\text { Test problem } \\
\text { no. }\end{array}$ & Problem no./type & $\begin{array}{l}\text { Number of } \\
\text { iterations }\end{array}$ & $\begin{array}{l}\text { Optimal objective } \\
\text { function value }\end{array}$ & $\begin{array}{l}\text { Optimal basic feasible solution (ignoring the } \\
\text { allocations in diagonal cells) }\end{array}$ \\
\hline 7.1 & Impaired Flow (P4) $P^{\prime}=40$ & 5 & 10 & $x_{14}=1, x_{23}=3, \mathrm{x}_{15}=3, \mathrm{x}_{25}=2, \mathrm{x}_{54}=5$ \\
\hline 7.2 & Enhanced Flow (P6) $P^{\prime}=48$ & 6 & 40 & $x_{14}=4, x_{34}=2, \mathrm{x}_{25}=5, \mathrm{x}_{53}=5$ \\
\hline 7.3 & Impaired Flow $(\mathrm{P} 4) P^{\prime}=115$ & 5 & 33 & $x_{12}=3, x_{23}=15, \mathrm{x}_{15}=5, \mathrm{x}_{54}=10$ \\
\hline 7.4 & Enhanced Flow (P6) $P^{\prime}=130$ & 5 & 80 & $x_{14}=8, x_{23}=22, x_{34}=2, \mathrm{x}_{25}=5, \mathrm{x}_{53}=10$ \\
\hline 7.5 & Impaired Flow (P4) $P^{\prime}=540$ & 17 & 82 & $\begin{array}{c}x_{23}=8, x_{2,10}=4, x_{38}=9, x_{39}=10, x_{43}=6 \\
x_{45}=9, x_{56}=6, x_{57}=11, x_{1,11}=10\end{array}$ \\
\hline 7.6 & Enhanced Flow $(\mathrm{P} 6) P^{\prime}=555$ & 12 & 119 & $\begin{array}{l}x_{12}=10, x_{23}=18, x_{2,10}=4, x_{38}=9, x_{39}=23, \\
x_{43}=9, x_{45}=6, x_{56}=8, x_{57}=11, x_{11,6}=5, \\
x_{3,11}=13\end{array}$ \\
\hline 7.7 & Case-I (P8) & 3 & 30 & $x_{14}=4, x_{23}=5, x_{34}=2, \mathrm{x}_{15}=3$ \\
\hline 7.8 & $(\mathrm{P} 10)$ & 5 & 23 & $x_{12}=3, x_{14}=1, x_{23}=8, x_{54}=5$ \\
\hline 7.9 & Case-II (P12) & 5 & 24 & $x_{12}=2, x_{14}=2, x_{23}=7, \mathrm{x}_{54}=8$ \\
\hline 7.10 & (P13) & 4 & 30 & $x_{14}=6, x_{23}=3, x_{15}=2, x_{25}=4$ \\
\hline 7.11 & Case-III (P14) & 4 & 36 & $x_{14}=7, x_{23}=10, x_{15}=1, x_{25}=8$ \\
\hline 7.12 & $(\mathrm{P} 15)$ & 6 & 36 & $x_{14}=4, x_{23}=10, x_{54}=11$ \\
\hline
\end{tabular}

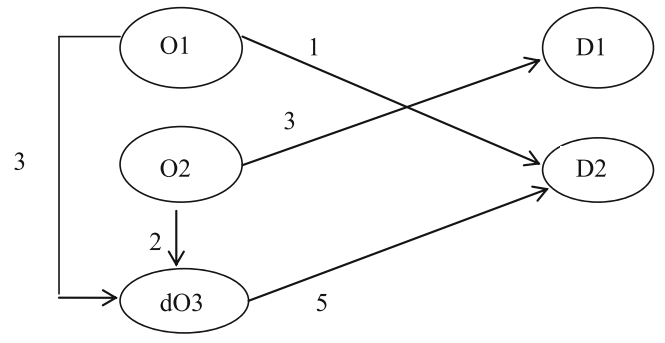

Fig. 3 Test problem 7.1

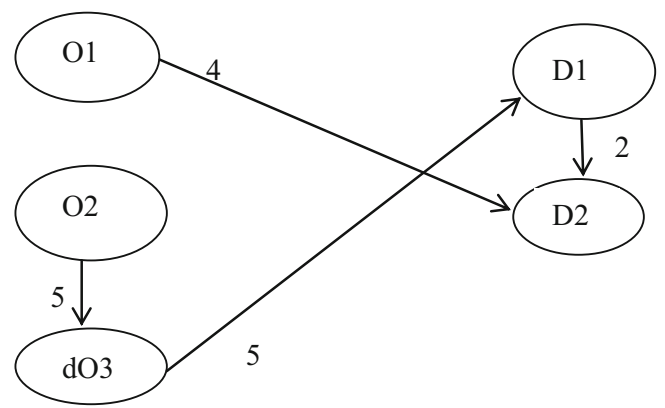

Fig. 4 Test problem 7.2

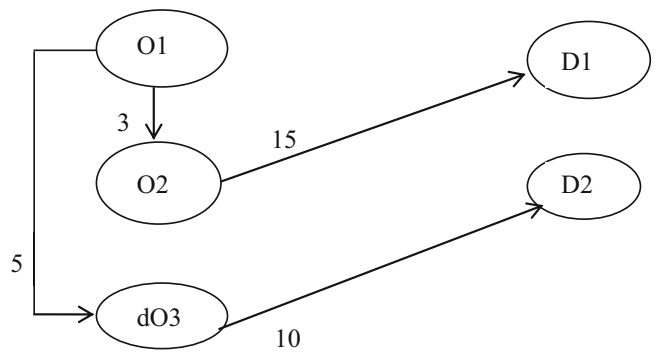

Fig. 5 Test problem 7.3

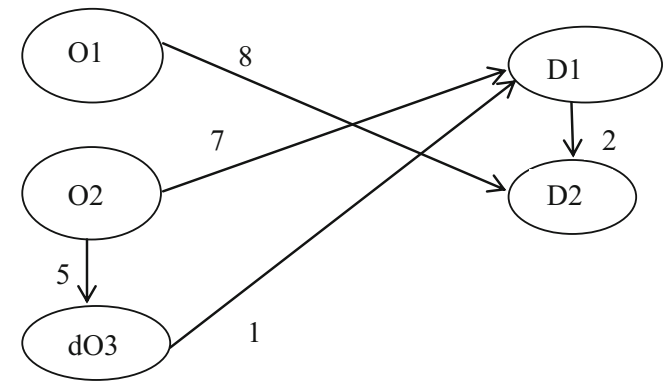

Fig. 6 Test problem 7.4

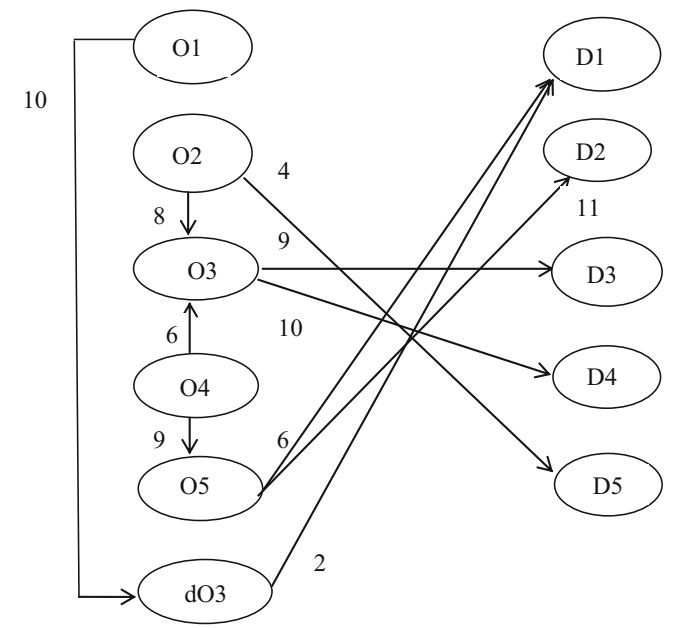

Fig. 7 Test problem 7.5 


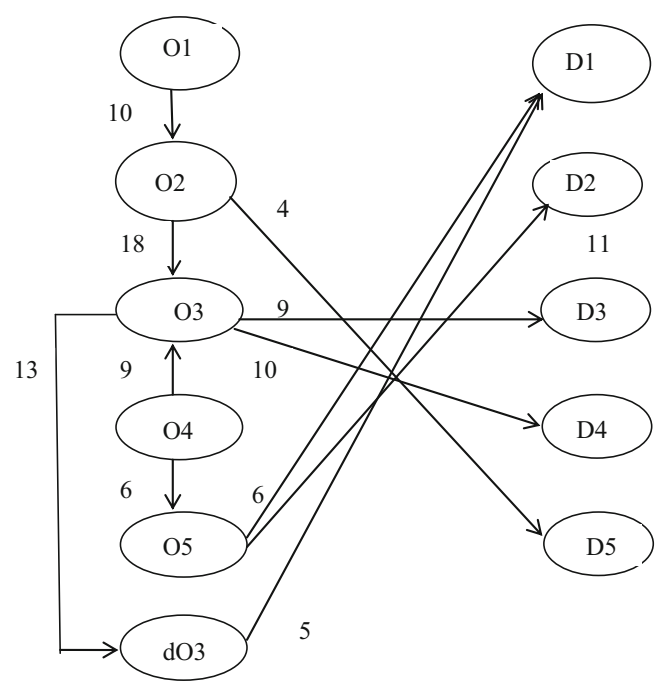

Fig. 8 Test problem 7.6

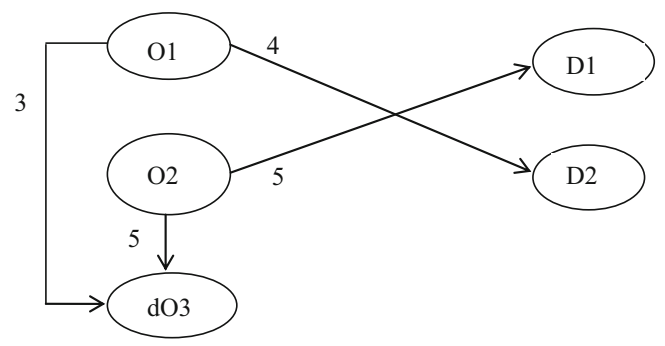

Fig. 9 Test problem 7.7

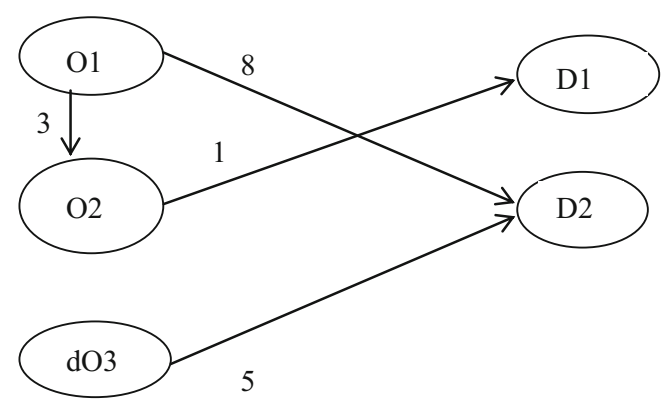

Fig. 10 Test problem 7.8

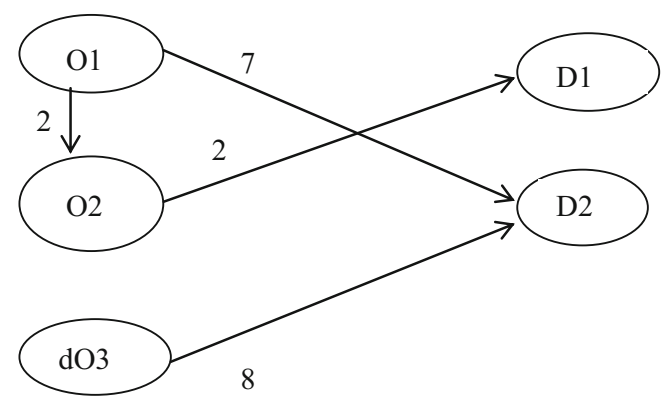

Fig. 11 Test problem 7.9

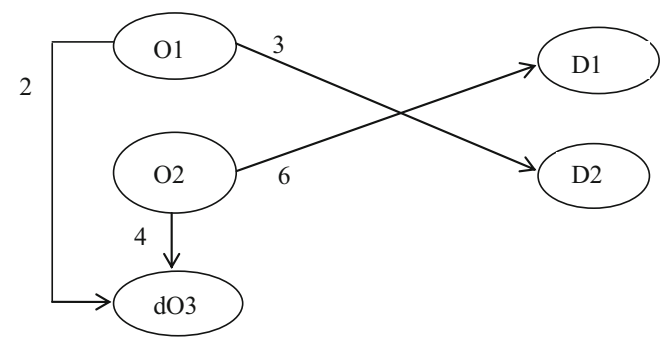

Fig. 12 Test problem 7.10

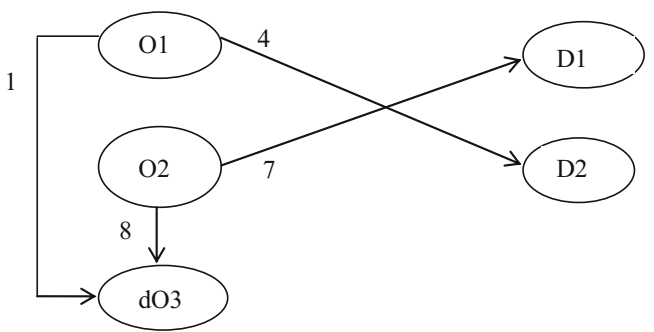

Fig. 13 Test problem 7.11

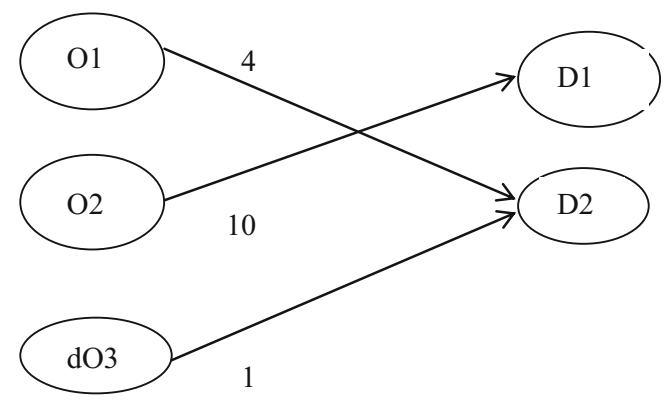

Fig. 14 Test problem 7.12

\section{Conclusion}

In the present paper the author has discussed various possible cases arising in linear transshipment problem with their solution methods. Sometimes, due to budget/political constraint, the decision maker may specify the total flow and the optimal solution of such problem is of practical interest to him. These solution methods shall be useful for the production allocation problems when the total flow in the market needs to be enhanced during festive /marriage seasons or during fire / military services or situations like financial problems which compels one to curtail the flow. Inspired by such situations we have studied transshipment problem with impaired and enhanced flow. Algorithms to solve the transshipment problems for the case of impaired and enhanced flow are developed by transforming the original problem into an equivalent transportation problem by adding an additional row and a column. It is shown that the optimal solution of the transformed transportation problem is same as the optimal solution of the original transshipment problem. Also there are 
many other situations emerging out of unbalanced transshipment problem which have also been discussed in the paper. The solution methods for both balanced as well unbalanced transshipment problems are being provided. The author has considered generalization of the standard transshipment model in which the origin and destination constraints take not only the equality form but also of inequality which is not covered in literature. The solution procedure is quite simple from computational point of view and is easy to understand and it serves the managers by providing a solution to variety of distribution problems. Thus the paper provides all potential variants of the transshipment problem with their solution methods. Numerical examples and computational work have also been done to illustrate the theory.

Acknowledgments The author is thankful to the University Grant Commission, Delhi, India for providing financial grant for carrying out the research work and is also grateful to her father Sh. B.D. Khurana who has always been the source of inspiration and strength for the author. The author is also thankful to referees for their valuable comments which helped in improving the paper.

Annexure

\section{GAMS program for transformed transportation problem of the Test problem 7.1}

sets origins / $1 * 5 /$, destinations / $1 * 5 /$;

table $\mathrm{C}$ (origins, destinations) cost of transportation

$\begin{array}{llllll} & 1 & 2 & 3 & 4 & 5 \\ 1 & 0 & 1 & 5 & 4 & 0 \\ 2 & 1 & 0 & 2 & 6 & 0 \\ 3 & 5 & 2 & 0 & 2 & 0 \\ 4 & 4 & 6 & 2 & 0 & 0 \\ 5 & 0 & 0 & 0 & 0 & 0\end{array}$

PARAMETER

destsum(origins)

/

$1 \quad 13$

214

39

49

$5 \quad 5 \quad /$

originsum(destinations)

/

19

29

$3 \quad 12$

$4 \quad 15$

55

nonnegative VARIABLES X(origins, destinations); 
VARIABLE

$\mathrm{Z}$ objective function;

EQUATIONS

obj

destsumequ(origins)

originsumequ(destinations);

obj.. $\mathrm{Z}=\mathrm{e}=\operatorname{sum}(($ origins, destinations), $\mathrm{x}$ (origins, destinations) $* \mathrm{C}($ origins, destinations $)$ );

destsumequ(origins).. sum(destinations, $\mathrm{x}$ (origins, destinations)) $=\mathrm{e}=$ destsum(origins);

originsumequ(destinations).. sum(origins, $\mathrm{x}$ (origins, destinations) $)=\mathrm{e}=$ originsum(destinations);

model impairedflowcosttransportation /all/

option solprint $=$ off;

option rmip = cplex;

option mip $=$ cplex;

option limrow $=800$;

option limcol $=600$;

option optca $=0$;

option optcr $=0$

option reslim $=5000$;

option iterlim $=10000000$;

option decimals $=3$;

solve impairedflowcosttransportation minimizing $\mathrm{Z}$ using MIP ;

display x.1

\section{GAMS program for transformed transportation problem of the Test problem 7.2}

sets origins $/ 1 * 5 /$, destinations $/ 1 * 5 /$;

table $\mathrm{C}$ (origins, destinations) processing time

$\begin{array}{lllll}1 & 2 & 3 & 4 & 5\end{array}$

$\begin{array}{llllll}1 & 0 & 1 & 5 & 4 & 4\end{array}$

$\begin{array}{llllll}2 & 1 & 0 & 2 & 6 & 2\end{array}$

$\begin{array}{llllll}3 & 5 & 2 & 0 & 2 & 2\end{array}$

$\begin{array}{llllll}4 & 4 & 6 & 2 & 0 & 4\end{array}$

$\begin{array}{llllll}5 & 4 & 2 & 2 & 4 & 1000\end{array}$

PARAMETER

destsum(origins)

/

$1 \quad 13$

$2 \quad 14$

39

49

$55 /$

originsum(destinations)

/

$\begin{array}{ll}1 & 9\end{array}$

29

$\begin{array}{ll}3 & 12\end{array}$

$4 \quad 15$

$55 /$ 
nonnegative VARIABLES X(origins, destinations);

VARIABLE

$\mathrm{Z}$ objective function ;

EQUATIONS

obj

destsumequ(origins)

originsumequ(destinations) ;

obj. $Z=\mathrm{e}=\operatorname{sum}\left(\left(\right.\right.$ origins, destinations), $\mathrm{x}$ (origins, destinations) ${ }^{*} \mathrm{C}$ (origins, destinations) $)$;

destsumequ(origins).. sum(destinations, $\mathrm{x}$ (origins,destinations) $)=\mathrm{e}=$ destsum(origins);

originsumequ(destinations).. sum(origins, $\mathrm{x}$ (origins, destinations) $)=\mathrm{e}=$ originsum(destinations);

model

enhancedflowcosttransportation /all/

option solprint $=$ off;

option rmip = cplex;

option mip $=$ cplex;

option limrow $=800$;

option limcol $=600$;

option optca $=0$;

option optcr $=0$;

option reslim $=5000$;

option iterlim $=10000000$;

option decimals $=3$;

solve enhancedflowcosttransportation minimizing $\mathrm{Z}$ using MIP ;

display x.1 ;

Open Access This article is distributed under the terms of the Creative Commons Attribution License which permits any use, distribution, and reproduction in any medium, provided the original author(s) and the source are credited.

\section{References}

1. Klingmana D, Russel R (1975) Solving constrained transportation problems. Oper Res 23(1):91-105

2. Brigden MEV (1974) A variant of transportation problem in which the constraints are of mixed type. Oper Res Quaterly 25(3):437-445

3. Gupta A, Khanna S, Puri MC (1992) Paradoxical situations in transportation problems. Cah Cent Etudesde Rech Operationnell 34:37-49

4. Gupta A, Khanna S, Puri MC (1993) A paradox in linear fractional transportation problems with mixed constraints. Optimization 27:375387

5. Khurana A, Thirwani D, Arora SR (2009) An algorithm for solving fixed charge bi-criterion indefinite quadratic transportation problem with restricted flow. Int J Optim Theory Methods Appl 1(4):367-380

6. Khurana A, Arora SR (2011) Fixed charge bi-criterion indefinite quadratic transportation problem with enhanced flow. Rev Investig Operacional 32:133-145
7. Arora SR, Khurana A (2004) Three dimensional fixed charge bicriterion indefinite quadratic transportation problem. Yugoslavia $\mathrm{J}$ Oper Res 14(1):83-97

8. Dahiya K, Verma V (2007) Capacitated transportation problem with bounds on the rim conditions. Eur J Oper Res 178:718-737

9. Orden A (1956) Transshipment problem. Manag Sci 2(3):276-285

10. King GA, Logan SH (1964) Optimum location, number, and size of processing plants with raw product and final product shipments. J Farm Econ 46:94-108

11. Rhody DH (1963) Interregional competitive position of the hog-pork industry in the southeast united States, unpublished Ph.D. thesis, Iowa State University

12. Judge GG, Havlicek J, Rizek RL (1965) An interregional model: its formulation and application to the livestock industry. Agric Econ Rev $17: 1-9$

13. Hurt VG, Tramel TE (1965) Alternative formulations of the transshipment problem. J Farm Econ 47(3):763-773

14. Garg R, Prakash S (1985) Time minimizing transshipment problem. Indian J Pure Appl Math 16(5):449-460

15. Khurana A, Verma T, Arora SR (2014) Solving time minimizing transshipment problem. International Journal of Shipping and Transport Logistics, Accepted for publication

16. Khurana A, Verma T, Arora SR (2012) An algorithm for solving time minimizing transshipment problem. Int J Manag Sci Eng Manag 7(3):192-199 
17. Thirwani D, Arora SR, Khanna S (1997) An algorithm for solving fixed charge bi-criterion transportation problem with restricted flow. Optimization 40:193-206

18. Khurana A, Arora SR (2006) The sum of a linear and a linear fractional transportation problem with restricted and enhanced flow. Int J Interdiscip Math 9(2):373-383

19. Khurana A, Arora SR (2011) Solving transshipment problems with mixed constraints. Int J Manag Sci Eng Manag 6(4):292297
20. Khurana A (2013) Multi-index fixed charge bi-criterion transshipment problem. OPSEARCH 50(2):229-249

21. Khurana A, Arora SR (2011) An algorithm for solving threedimensional transshipment problem. Int J Math Oper Res 4(2):97113

22. Khurana A,Verma T (2014) On a class of capacitated transshipment problems with bounds on rim conditions, International Journal of Mathematics of Operational Research, Accepted for publication 